\title{
Genetic and clinical studies in autosomal dominant polycystic kidney disease type 1 (ADPKD1)
}

\author{
Eliecer Coto, Sixto Aguado, Jaime Alvarez, María J Menéndez Díaz, \\ Carlos López-Larrea
}

\begin{abstract}
Thirteen Spanish families with autosomal dominant polycystic kidney disease were studied. In one family the disease did not segregate with polymorphic markers around the PKD1 locus. All subjects over the age of $\mathbf{3 0}$ years carrying a mutation at the PKD1 locus showed renal ultrasonographic cysts, but $40 \%$ of carriers of the PKD1 mutation younger than 30 years did not have renal cysts. Hypertension was found to be more frequent in those with renal cysts. Recombinants between 16p polymorphic loci and the PKD1 locus are described.
\end{abstract}

Autosomal dominant polycystic kidney disease (ADPKD) is one of the most common inherited diseases in man. The frequency of carriers of a mutant gene causing this disease has been estimated as 1 in 1000 persons. About $10 \%$ of cases of end stage renal failure in Caucasians is caused by this disease. ${ }^{1}$ Affected subjects can be diagnosed before symptoms develop if they have renal cysts, detected by ultrasonographic imaging of the kidney. However, the number and size of cysts increases with age and they are usually not detected in children. ${ }^{23}$ This age factor has to be taken into account when interpreting negative ultrasonographic findings. Variability between affected subjects is also found in other clinical parameters. Therefore, the age of onset of renal dysfunction in ADPKD varies widely, with a considerable proportion remaining asymptomatic during their life. Urinary tract infections, hypertension, and raised serum creatinine levels have been associated with ADPKD in some studies. ${ }^{4-6}$ Significant positive linkage between DNA polymorphic markers on the short arm of chromosome 16 (16p) and $A D P K D$ was established in a number of affected families from Europe and North America. ${ }^{7-11}$ This locus has been designated PKD1. In about $5 \%$ of ADPKD families the disease is not linked to markers on $16 \mathrm{p}$ owing to mutations elsewhere in the genome. This is an alternative form of ADPKD. ${ }^{12}{ }^{13}$ Genetic studies with DNA probes from regions both proximal and distal to the PKD1 locus are currently performed for carrier detection of the disease in affected families. ${ }^{1415}$ A sufficient number of affected subjects, as detected by ultrasonographic imaging, is necessary to establish linkage between the disease and the polymorphic markers closely linked to $P K D 1$ in any family (ADPKD1 families) before determining the risk for any asymptomatic subject. ${ }^{15}$

We have studied 13 large Spanish families with autosomal dominant polycystic kidney disease in an attempt to determine the incidence of the alternative form and to compare the specificity and sensitivity of ultrasonographic and DNA studies in the ADPKD1 families. Finally, our results were compared with those from other previously reported studies.

\section{Material and methods}

SELECTION OF FAMILIES AND

ULTRASONOGRAPHIC DIAGNOSIS

Thirteen families with at least three affected and two unaffected members were included in our study. This minimum number of family members with clinical findings was established by the European concerted action project 'Towards prevention of renal failure caused by polycystic kidney disease'. These criteria were used in previous studies and can be considered to be restrictive. ${ }^{16}$

Autosomal polycystic kidney disease was diagnosed by ultrasonography. Subjects who showed at least one cyst in each kidney or more than one cyst in one kidney were considered affected. These diagnostic criteria were used in previously reported studies. ${ }^{216}$

\section{GENETIC STUDIES}

Seven polymorphic markers around the PKD1 locus were used. $3^{\prime}$-HVR and $41 \cdot 1$, the more distal and proximal loci, are $5 \mathrm{cM}$ and $6 \mathrm{cM}$ respectively from $P K D 1$. The other probes used were HMJ1 and pGGG1, which identify polymorphisms distal to $P K D 1$, and 26.6 , VK $5 \mathrm{~b}$, and $24 \cdot 1$, which identify polymorphisms between the PKD1 and the centromere of chromosome 16. Restriction enzymes detecting polymorphisms for these markers, allele sizes, and frequencies have been previously published, as well as a map of these loci on the short arm of chromosome $16 .{ }^{11}$ Genomic DNA extraction, digestion, electrophoresis, transfer of DNA to nylon membranes, labelling of probes, hybridisation, and washing of membranes were performed following previously described protocols. ${ }^{17}$ Autosomal polycystic kidney disease was considered to be the classical 16p linked form in those families in which all affected members coinherited the 
Family 13

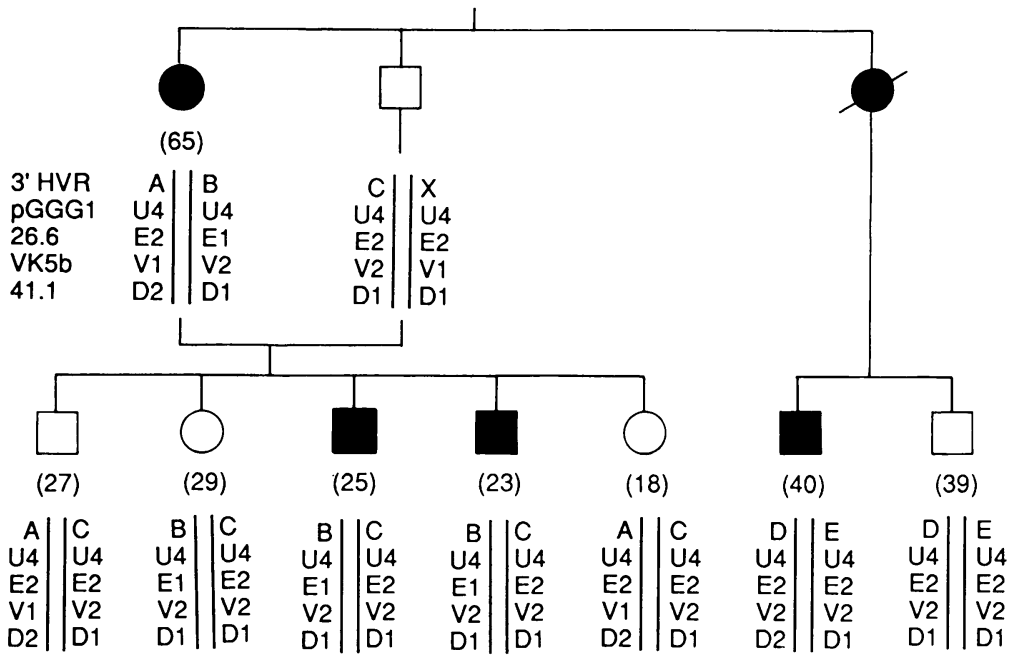

Figure 1 Pedigree of PKD family 13. In this family the disease is not linked to polymorphic markers on the short arm of chromosome 16.
Table 1 Maximum lod score ( $Z$ ) between the PKD1 and $3^{\prime}-H V R$ loci. The recombination fraction $(\theta)$ for the maximum lod score is shown in brackets.

\begin{tabular}{cccc}
\hline $\begin{array}{c}\text { No of } \\
\text { informative } \\
\text { families }\end{array}$ & $\begin{array}{c}\text { No of } \\
\text { generations }\end{array}$ & $\begin{array}{c}\text { No of persons } \\
\text { with renal } \\
\text { cysts }\end{array}$ & Zmax $(\theta)$ \\
\hline 1 & 3 & 3 & $1.85(0.00)$ \\
2 & 3 & 3 & $1.40(0.00)$ \\
3 & 2 & 3 & $1.70(0.00)$ \\
4 & 3 & 4 & $1.75(0.00)$ \\
5 & 2 & 6 & $2.30(0.00)$ \\
6 & 2 & 7 & $2.70(0.05)$ \\
7 & 3 & 3 & $1.60(0.05)$ \\
8 & 3 & 3 & $2.30(0.00)$ \\
9 & 3 & 5 & $2.35(0.00)$ \\
10 & 3 & 11 & $2.85(0.05)$ \\
11 & 2 & 6 & $3.10(0.00)$ \\
12 & 2 & 5 & $1.90(0.00)$ \\
\hline
\end{tabular}

alleles predicted as segregating with the mutant PKD1 allele. Unaffected subjects could have inherited any haplotype characterised as not carrying the PKD1 mutation. When a family had two or more members in whom the presence of cystic kidneys did not cosegregate with alleles at loci flanking the PKD1 locus, they were considered to have the alternative form of adult dominant polycystic kidney disease. Linkage studies were performed on the 13 families. The decimal logarithm of the odds ratio for linkage (lod score, $Z$ ) was estimated at different recombination frequencies $(\theta)$ using the LINKAGE program. ${ }^{18}$

Results

Thirteen ADPKD families from northern Spain were studied. Members of these families were diagnosed as affected or unaffected by ultrasonography. The combined use of the highly polymorphic marker 3 '-HVR, distal to the PKD1 locus, and the four proximal markers, $26 \cdot 6$, VK5b, $24 \cdot 1$, and $41 \cdot 1$, allowed us to assign both haplotypes unambiguously for each family member. Evidence of no linkage of the disease to markers on $16 p$ was found in one family (fig 1). In this family the disorder is the result of a mutation elsewhere in the genome. In the 12 ADPKD1 families, recombinants between the PKD1 locus and polymorphic loci 3'-HVR, HMJ1, 24.1, and $26 \cdot 6$ were identified (table 1). A recombination between 26.6 and $P K D 1$ in one large family was found (fig 2) and it is hoped that this family will contribute to a better definition of the region containing the PKD1 locus. Recombinants between a gene and the most closely linked polymorphic loci are necessary for the cloning of the gene by using the 'reverse genetic' protocol. ${ }^{19}$ Age dependence of development of kidney cysts was found by ultrasonographic examination of 101 symptomatic or at risk subjects (children of affected persons) from the $12 \mathrm{ADPKD} 1$ families (table 2). Among 50 members of the ADPKD1 families who were less than 30 years old, 27 $(54 \%)$ were carriers of the disease (PKD1 carriers) and $40 \%$ of these $(11 / 27)$ did not have renal cysts. Thirty-seven of the $51(73 \%)$ members of ADPKD1 families who were 30 years or older had renal cysts. No asymptomatic subjects carrying a PKD1 mutation were found in this group. disease was detected or the age of the last ultrasonographic examination. Asterisks indicate the haplotype carrying the PKD1 mutation. Arrows between loci indicate recombinant haplotypes. Subject $I(58)$ is a recombinant between the PKD1 and the 26.6 loci. The maximum lod score for linkage $(Z=2.85)$ between PKD1 and the highly polymorphic marker $3^{\prime}-H V R$ was obtained at a recombination fraction of 0.05 . This value represents odds in favour of linkage of 708 to 1. 
Thirteen of the affected subjects had end stage renal disease. The earliest age and the mean age at onset of end stage renal disease was 30 and 52 years, respectively. Hypertension has been described as being more frequent among persons with polycystic kidney disease. Hypertension was present in the 40 symptomatic members without end stage renal disease from our ADPKD1 families as compared with 33 asymptomatic ones. Fifteen subjects (38\%) in the symptomatic group and three $(6 \%)$ in the asymptomatic group had hypertension.

\section{Discussion}

We have studied 13 ADPKD families from northern Spain, who came from the same region, Asturias, which has a population of about 1 million. To obtain a sufficient number of family members to determine the linkage between dominant polycystic kidney disease and polymorphic markers on the short arm of chromosome 16, it has been necessary to study any affected family, since genetic heterogeneity for this disease has been described. During the years 1989 to 1990 we have accumulated clinical information and biological samples from 25 families. Even though only 13 of them $(48 \%)$ were large enough to be studied, this proportion was higher than that obtained in regions with a larger population; here technical facilities are better but geographical dispersion of family members makes the accumulation of sufficient data difficult. As compared with others previously reported, our study shows similar genetic and clinical findings. As in other populations, we have identified at least one family in which the PKD1 locus does not map on the short arm of chromosome 16. The number of families included in our study was not large enough to determine the incidence of the alternative form in our population. However, other studies, including a similar number of families (10 to 15) from different populations, have found at least one non-ADPKD1 family. This indicates that the number of families in which the disease does not map on the short arm of chromosome 16 is greater than previously estimated $(5 \%)$. The earliest age ( 30 years) and mean age ( 52 years) at onset of end stage renal disease is not different from that found in other populations. Parfrey et $a l^{16}$ found similar values (30 and 60 years old) in 15 families from Labrador (Canada). An absence of cysts on ultrasonography was not found in carriers of a PKD1 mutation older than 30 years. This, in addition to the low frequency of the non-16p linked

Table 2 Total number of subjects from the 12 ADPKD1 families characterised by age as symptomatic/PKD1 mutation carriers (cysts + /RFLPs+), asymptomatic) PKD1 mutation carriers (cysts-/RFLPst), and asymptomatic/not PKD1 mutation carriers (cysts-/RFLPs-).

\begin{tabular}{lcccccc}
\hline & \multicolumn{2}{c}{$\begin{array}{c}\text { Less than } \\
\end{array}$} & & \multicolumn{2}{c}{$\begin{array}{c}\text { More than } \\
\end{array}$} & \multicolumn{2}{c}{ years old } & & \multicolumn{3}{c}{ years old } \\
\cline { 2 - 3 } \cline { 6 - 7 } & No & $\%$ & & No & $\%$ \\
\hline Cysts +/RFLPs + & 16 & 32 & & 37 & 73 \\
Cysts-/RFLPs + & 11 & 22 & & 0 & 0 \\
Cysts-/RFLPs - & 23 & 46 & & 14 & 27 \\
\hline
\end{tabular}

form of ADPKD, determines that diagnosis can be made by ultrasonographic detection of cysts with a very low risk of false diagnosis in persons older than 30 years. This is especially important in a disease for which a large number of family members is necessary when genetic counselling using DNA polymorphic markers is required. However, because $40 \%$ of disease carriers younger than 30 years do not show cysts on ultrasonography, the use of polymorphic markers around the PKD1 locus is necessary for this age group if a presymptomatic diagnosis is required.

Finally, at the moment, genetic studies in adult dominant polycystic kidney disease are laborious compared with other genetic diseases for which small families and only two or three polymorphic DNA markers are sufficient, such as cystic fibrosis. In addition, prenatal diagnosis is only recommended if extensive family studies have been done before pregnancy. Data from the present and other previously published and future studies will contribute to a better knowledge of this disease with the major aim of developing an intervention procedure that retards or prevents the progression of renal disease.

The authors wish to thank Dr M H Breuning (Department of Human Genetics, Sylvius Laboratory, University of Leiden, Leiden, The Netherlands) for providing the probes and the computer programs used in the linkage studies. This work was supported by grant FISS $89 / 2548$. MJMD is recipient of a FICYT grant.

1 McKusick VA. Mendelian inheritance in man. Catalogs of autosomal dominant, autosomal recessive and $X$-linked phenotypes. 8th ed. Baltimore: Johns Hopkins University Press, 1988

2 Bear JC, McManamon P, Morgan J, et al. Age at clinical onset and at ultrasonographic detection of adult polycystic kidney disease: data for genetic counseling. $A m \mathcal{F} \mathrm{Med}$ Genet 1984;18:45-53.

3 Dalgaard OZ. Polycystic disease of the kidneys. In: Strauss MB, Welt LG, eds. Disease of the kidneys. Boston: Little, Brown \& Co, 1963:1223-58.

4 Churchill DN, Bear JC, Morgan J, et al. Prognosis of adult onset polycystic kidney disease re-evaluated. Kidney Int 1984;26:190-3.

5 Bell PE, Hossack KF, Gabow PA, et al. Hypertension in autosomal dominant polycystic kidney disease. Kidney Int 1988;34:683-90.

6 Hossack KF, Leddy CH, Johnson AM, Schrier W, Gabow PA. Echocardiographic findings in autosomal dominant PA. Echocardiographic findings in autosomal dominant

7 Reeders ST, Breuning MH, Davies KE, et al. A highly peeders ST, Breuning MH, Davies KE, et al. A highly
polymorphic DNA marker linked to adult polycystic kidney disease on chromosome 16. Nature 1985 317:542-4.

8 Breuning $\mathrm{MH}$, Reeders ST, Brunner $\mathrm{H}$, et al. Improved early diagnosis of adult dominant polycystic kidney disease with flanking DNA markers. Lancet 1987;ii:1359-61.

9 Reeders ST, Breuning MH, Ryyanen ME, et al. A study of linkage heterogeneity in adult dominant polycystic kidney disease. Hum Genet 1987;76:348-51.

10 Reeders ST, Breuning MH, Corney G, et al. Two genetic markers closely linked to adult polycystic kidney disease on chromosome 16 . BMf 1986;292:851-3.

11 Breuning $\mathrm{MH}$, Snijdewint FGM, Brunner $\mathrm{H}$, et al. Map of 16 polymorphic loci on the short arm of chromosome 16 close to the polycystic kidney disease gene (PKD1). 7 Med Genet 1990;27:603-13.

12 Romeo G, Devoto M, Costa G, et al. A second genetic locus for autosomal dominant polycystic kidney disease. Lancet 1988;ii:8-11.

13 Kimberling WJ, Fain PR, Kenyon JB, et al. Linkage heterogeneity of autosomal polycystic kidney disease. $N$ heterogeneity of autosomal poly

14 Reeders ST, Zerres K, Gal A, et al. Prenatal diagnosis of autosomal dominant polycystic kidney disease with a DNA probe. Lancet 1986;ii:6-8.

15 Breuning MH, Snijdewint FGM, Dauwerse JG, et al. Two step procedure for early diagnosis of polycystic kidney step procedure for early diagnosis of polycystic kidney
disease with polymorphic DNA markers on both sides of the gene. $\mathcal{f}$ Med Genet 1990;27:614-7. 
16 Parfrey PS, Bear JC, Morgan J, et al. The diagnosis and prognosis of autosomal dominant polycystic kidney disease. N Engl f Med 1990;323:1085-90.

17 Old JM. Fetal DNA analysis. In: Davies KE, ed. Human genetic disease. A practical approach. Oxford: IRL Press,
1986:1-17.
18 Ott J. A short guide to linkage analysis. In: Davies KE, ed. Human genetic disease. A practical approach. Oxford: IRI Press, 1986:19-32.

19 Rommens JM, Iannuzzi MC, Kerem BS, et al. Identification of the cystic fibrosis gene: chromosome walking and jumping. Science 1989;245:1059-65. 